\title{
The new age of global health governance holds promise
}

\author{
Tikki Pang ${ }^{1}$, Nils Daulaire ${ }^{2}$, Gerald Keusch ${ }^{3}$, Rose Leke ${ }^{4}$, Peter Piot ${ }^{5}$, Srinath Reddy ${ }^{6}$, Andrzej Rys ${ }^{7}$ \& Nicole Szlezak ${ }^{8,9}$
}

\begin{abstract}
The recognition that many diseases present worldwide challenges has spurred nations and institutions to participate in the development of what is known as 'global health governance'. But this new form of governance will only succeed with strengthened country commitment, collaborations across disparate sectors and improved accountability.
\end{abstract}

In an era of rapid globalization, the world faces serious global threats to human health, including infectious and chronic diseases, antimicrobial resistance and inequitable access to medicines. Fortunately, since the mid-1990s, recognition of a need for action on global health has led to the creation of many new initiatives and mobilization of unprecedented resources.

Diseases do not recognize national boundaries, so tackling such illnesses requires collective action through effective global health governance (GHG), defined as the formal and informal institutions, norms and processes that govern or directly influence health policy and outcomes worldwide. To date, the institutional structures for collective action have mostly evolved in an ad hoc, rather than systematic, manner. State and nonstate actors pursue their various priorities with sometimes markedly different approaches. For example, states support multilateral initiatives, such as the Global Fund to Fight AIDS, Tuberculosis and Malaria, which improve access to medicines; meanwhile, nonstate actors, such as the Bill and Melinda Gates Foundation, directly support research institutions to develop new health interventions.

Whether there should be a single global health authority to allocate responsibilities and resources is debatable. Notwithstanding the existence of the 2005 Paris Declaration, in which governments pledged harmonization and alignment of the aid they provide, some would consider the idea of such a GHG authority an illusion. But there is no doubt that an absence of effective GHG will exacerbate the current fragmentation of objectives and poor coordination of supported activities, as well as the narrow focus on short-term results, large transaction costs on recipients and the lack of accountability.

Much experience has been gained in recent years with global health initiatives; a recent dialogue at the World Health Summit Working Session on Global Health Governance in Berlin last month identified three key messages for improving GHG in the future.

National authorities should be in the driver's seat in allocating donor money - but they must also pull their weight in improving conditions locally. Countries need to invest more of their own resources for health improvement and not rely mainly on external aid. They must strengthen their own capacities for better national governance, as progress globally ultimately depends on strong national health systems (PLoS Med. 7, doi:10.1371/journal.pmed.1000089, 2010). This includes the capacity to negotiate with donors, to access resources that may be controlled by ministries other than the ministry of health (e.g. the ministry of finance), to allocate resources at the most appropriate level (national, district or local), to evaluate the impact of initiatives and to write proposals that are better aligned with national health needs.

Action across sectors is needed. Complex health challenges, such as HIV/AIDS, cancer, diabetes and cardiovascular diseases, require the involvement of many players beyond the health sector. Health is inextricably linked to human development; thus, effective governance must be linked to, for example, the emerging field of global health diplomacy, which lies at the interface of health, foreign policy and trade.

Partnerships should be democratic, inclusive and accountable. Going forward, partnerships in the global health sphere need to have three key characteristics: these alliances should be democratic, representing a level playing field' for all parties involved; inclusive, involving the private sector and civil society, helping all countries in need (and not just selected 'darling countries' of donors) and recognizing the importance of middle-income developing countries (for example, China, Brazil and India) as growing partners in health improvement efforts in a wide range of low-income countries; and accountable, incorporating independent evaluation of initiatives, which should be a prerequisite for such collaboration.

Similar themes were highlighted at the UN Summit on the Millennium Development Goals in New York in September, which reiterated the importance of country ownership of both the funding agenda and the administration of support, as well as the need for better alignment and accountability for results.

At the World Health Summit, there was a palpable sense of renewed commitment from some key stakeholders. This includes the convergence in objectives of major recent initiatives from the US and the EU and stronger linkages of these initiatives with agencies such as the Global Fund. There is also better awareness of the need for reform within the World Health Organization (WHO) so that it can play a stronger leadership role in GHG.

Increasingly, initiatives (such as the Global Fund and the Global Alliance for Vaccines and Immunization) are also demand driven rather than supply driven. These relatively recent ventures represent examples where GHG has succeeded in providing much-needed medicines and vaccines to the developing world. Although UN organizations should still have a central role, the future involvement in GHG of other highlevel political entities (for example, the G20 and G8) should also be considered.

Health is global, but implementation is always local. A prime challenge is to resolve the tension between the need for results and local ownership and capacity building. Ultimately, those in greatest need should have a big say in setting the agenda.

Now that global health has gained recognition as a fundamental concept, the movement toward establishing effective GHG has begun; attention to signals from both donors and recipients will point to ways of improving it. Harmony and coordination is arguably necessary to ensure that GHG benefits those in greatest need. And emphasizing the underlying values of GHG - its value as a 'global public good' and its objectives of ensuring human dignity and serving underprivileged populations - as well defining its boundaries will be crucial to improving health going forward.

${ }^{1}$ Research Policy \& Cooperation, World Health Organization, Geneva, Switzerland. ${ }^{2}$ Office of Global Health Affairs, US Department of Health and Human Services, Washington, DC, USA. ${ }^{3}$ Boston University, Boston, Massachusetts, USA. ${ }^{4}$ University of Yaoundé 1, Yaoundé, Cameroon. ${ }^{5}$ London School of Hygiene \& Tropical Medicine, London, UK. ${ }^{6}$ Public Health Foundation of India, New Delhi, India. ${ }^{7}$ European Commission, Luxembourg. ${ }^{8}$ McKinsey \& Company, Berlin, Germany ${ }^{9}$ Sustainability Science Program, John F. Kennedy School of Government, Harvard University, Cambridge, Massachusetts, USA. 